\title{
Factoren die de keuze van patiënten voor zorgaanbieders in europese en noord-amerikaanse landen bepalen
}

\author{
Anne van Els \\ Maastricht University \\ a.vanels@student.maastrichtuniversity.nl
}

\begin{abstract}
Introduction: Since the introduction of a market oriented structure in public health care patients are expected to make informed choices between health care providers. However, it is still unclear what patients base their decisions on. The objective of this literature study is to identify the personal, healthcare provider-related, logistic and financial factors which determine the patients' choice for certain healthcare providers. More specifically, only determinants of choice for surgical hospital care in European and North-American countries are studied. Method: Articles were mainly derived from the Pubmed, Medline and Google Scholar databases. Search terms used were patient choice, provider, physician and hospital. Furthermore, 3 additional articles were provided by the supervisors and 8 articles were included by backwards referencing. After inclusion, the articles were analyzed by the simple approach. Results: 27 articles were taken into account for analyses. Personal factors that influence the patient's choice for a certain provider are age, race, medical condition, educational level, earlier experiences and the advice of people in the social network of patients. Furthermore, provider related factors which often came forward were the expertise of staff, the number of services offered, reputation and the quality of care provided. Moreover, the type of organization and the size of hospitals have an impact on the choice. Important logistic aspects are the distance to the hospital, the waiting time before treatment and the travel options. Financial aspects which are considered in advance of choosing are the costs of treatment, the costs of travelling and the personal expenses. Conclusion: It can be concluded that many factors determine the patient's choice. However, it is difficult to indicate the importance of all the factors found because often combinations of factors or interactions between factors determine the patient's choice.
\end{abstract}


Keywords

Patient choice, choice behaviour, health care provider, hospital

\section{Introductie}

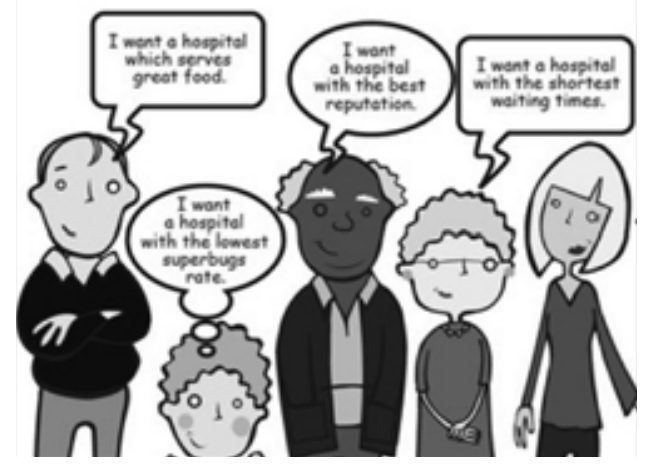

Door de invoering van marktwerking in de zorg is de patiënt meer centraal komen te staan. Van de patiënt wordt verwacht dat deze zich kritisch opstelt en rationele keuzes maakt tussen zorgaanbieders. De achterliggende gedachte hiervan is dat het actief kiezen de zorgaanbieders stimuleert om kwalitatief goede zorg te leveren, efficiëntie te verhogen, wachtlijsten te verminderen en de hoge zorgkosten te reduceren. Hoewel de keuzes van patiënten dus een grote rol spelen binnen de marktwerking en in de totale zorgsector, is het nog altijd onduidelijk waar patiënten hun keuze voor een zorgaanbieder op baseren. Het doel van deze thesis is dan ook om persoons-gerelateerde, zorgaanbieder-gebonden, logistieke en financiële aspecten te identificeren die de keuze van patiënten bepalen.

Het literatuuronderzoek richt zich specifiek op snijdende medisch specialistische zorg in Europese en Noord-Amerikaanse landen. De medisch specialistische zorg, ook wel ziekenhuiszorg genoemd, omvat alle zorg die wordt geleverd door medisch specialisten in onder andere algemene ziekenhuizen en universitaire medische centra, categorale instellingen, en zelfstandige behandelcentra. De toevoeging snijdend maakt duidelijk dat in deze thesis enkel studies bestudeerd worden waarin sprake is van chirurgische of heelkundige zorg. Tevens wordt de verloskundige zorg ook tot het snijdend specialisme gerekend. Ondersteunende en beschouwende (niet-snijdende) zorgverleningsprocessen worden in dit onderzoek buiten beschouwing gelaten omdat wordt verondersteld dat bij elk van deze vormen van zorg andere factoren invloed uitoefenen op de keuze voor een zorgaanbieder. Voor de specificatie van landen is gekozen omdat er grote verschillen bestaan tussen landen binnen en buiten Noord-Amerika en Europa wat betreft het gezondheidszorgsysteem en het verzekeringsstelsel. Verder worden in deze thesis enkel electieve patiëntenstromen in ogenschouw genomen omdat er bij acute problematiek niet de tijd en mogelijkheid is om een weloverwogen keuze te maken. 
Wanneer de keuzecriteria geïdentificeerd zijn, kan de zorg beter worden afgestemd op de wensen en behoefte van de patiënten. Als bekend is wat patiënten waarderen kan hier namelijk rekening mee worden gehouden. Daarnaast heeft het ook een duidelijk voordeel voor de zorgaanbieders. Specialisten, klinieken en ziekenhuizen weten dan namelijk hoe zij zich het beste kunnen profileren naar patiënten. Met voor de patiënt waardevolle investeringen en veel gerichtere communicatie kan een competitief voordeel ten opzichte van andere zorgaanbieders worden behaald.

\section{Methode}

Om de exploratieve onderzoeksvraag te beantwoorden is een literatuuronderzoek gedaan naar de factoren die de keuze van patiënten voor een zorgaanbieder bepalen. Binnen de databases van Pubmed, Medline en Google Scholar is met de zoektermen 'patient choice', 'provider', 'physician' en 'hospital' gezocht naar bruikbare artikelen. Verder zijn 3 extra artikelen aangedragen door de begeleiders en zijn 8 artikelen geïncludeerd vanuit de referentielijsten. Inclusiecriteria zijn de toegang tot de volledige tekst, Engels of Nederlands schrift en de publicatie in een wetenschappelijk tijdschrift. Bovendien zijn artikelen ouder dan 10 jaar en artikelen afkomstig uit andere dan Europese of NoordAmerikaanse landen geëxcludeerd. Tevens moesten de geselecteerde studies zich hebben gericht op snijdende medisch specialistische zorg.

Tabel 1. Zoektermen \& aantal resultaten per database

\begin{tabular}{lll} 
Database & Zoektermen & Aantal resultaten \\
\hline Pubmed & $\begin{array}{l}\text { provider* OR hospital* OR physician* (title/abstract) } \\
\text { AND patient choice (title) }\end{array}$ & 83 \\
\hline Medline & $\begin{array}{l}\text { provider* OR hospital* OR physician* (abstract) AND patient } \\
\text { choice (title) }\end{array}$ & 71 \\
\hline Google Scholar & $\begin{array}{l}\text { allintitle: choice, patient OR patients OR patient's, provider } \\
\text { OR providers OR hospital OR hospitals OR determinants }\end{array}$ & 172 \\
\hline
\end{tabular}

Vervolgens zijn de geïncludeerde artikelen geanalyseerd aan de hand van de 'simple approach'. Dit houdt in dat informatie die bruikbaar was om de hoofdvraag te beantwoorden in tekst werd samengevat en is weergegeven in een tabel. Per artikel werden tevens verschillende details genoteerd. Hierbij ging het onder andere om algemene publicatie informatie en de onderzoeksmethode, maar ook over het land, de zorginstelling of zorgaanbieder en de ziekte waar het onderzoek betrekking op had. Bovendien werden 
de gevonden resultaten met elkaar vergeleken. Wanneer niet enkel overeenkomsten maar ook verschillen werden gevonden zijn de context en beperkingen van de tegenstrijdige bronnen beoordeeld.

\section{Resultaten}

De opgestelde zoekstrategieën leverde in totaal 326 resultaten op. Echter zijn er na toepassing van de in- en exclusiecriteria en het lezen van titels en abstracts slechts 16 artikelen geselecteerd. Tevens zijn 8 artikelen geïncludeerd vanuit de referentielijsten van eerder geselecteerde literatuurreviews en hoofdartikelen. Daarbovenop komen 3 artikelen die zijn verkregen via de begeleiders. Het totale aantal geïncludeerde studies $(n)$ is 27 .

\section{Persoonsgebonden factoren}

De term persoonsgebonden is in relatief brede vorm gehanteerd, waardoor niet enkel demografische kenmerken maar ook gezondheids-gerelateerde aspecten en het sociaal netwerk van de patiënt aan bod komen. In 17 van de 27 onderzochte artikelen is aandacht besteed aan deze categorie. Uit verschillende studies is naar voren gekomen dat de factoren als leeftijd, ras en woonomgeving een significante rol spelen in het keuzeproces van electieve patiënten. Tevens is de factor geslacht onderzocht. Wat leeftijd betreft zijn de personen die kiezen voor een zorgaanbieder buiten zijn of haar woonprovincie gemiddeld jonger dan de patiënten die blijven bij hun vaste en/of dichtstbijzijnde zorgaanbieder . Bovendien kiezen ouderen patiënten, zelfs als ze door een andere zorgaanbieder eerder kunnen worden behandeld, minder snel om over te stappen dan jongere patiënten. Echter wordt door zowel Roh (1) als Varkevisser (2) aangetoond dat er ook een positieve relatie kan bestaan tussen de leeftijd van patiënten en de waarschijnlijkheid dat het dichtstbijzijnde ziekenhuis wordt omzeild. Wat geslacht betreft zijn er verschillen gevonden in de mate waarin factoren bepalend zijn. Zo is het voor vrouwelijke patiënten bijvoorbeeld belangrijker dan voor mannelijke patiënten dat de zorginstelling positieve reclame krijgt vanuit de pers (3). Verder blijken vrouwelijke plattelands patiënten vaker dan hun mannelijke tegenhangers een stadsziekenhuis te verkiezen boven het lokale plattelandsziekenhuis (4). In tegenstelling tot het voorafgaande is in de studie van Weir et al. (5) gevonden dat er geen verschil bestond in de geprefereerde invloeden tussen mannen en vrouwen. Ook is er in dat onderzoek geen significant verschil tussen jongere en oudere patiënten waargenomen (5). Bovendien is in de studie van Moscone et al. (6) geen significante invloed van geslacht of leeftijd gevonden.Varkevisser (2) vond eveneens geen significant effect van geslacht. 
Socio-economische kenmerken als sociale economische status (opgesplitst in werkstatus en inkomen), tijd en opleidingsniveau oefenen invloed uit op de keuze van patiënten voor een bepaalde zorgaanbieder. Het hebben van genoeg tijd is een vereiste als men actief wil kiezen tussen zorgaanbieders. Het zoekproces neemt namelijk de nodige tijd in beslag. Het opleidingsniveau bepaald voornamelijk welke factoren, uitkomstmaten of bronnen patiënten in ogenschouw nemen alvorens ze een beslissing nemen. Gerelateerd aan het opleidingsniveau is de kennis (geletterdheid en rekenkundigheid) van zorg. Wanneer de capaciteiten die men nodig heeft om de zorg gerelateerde basisinformatie te kunnen verkrijgen en te kunnen verwerken niet aanwezig zijn is het erg lastig een rationele keuze te maken.

De medische conditie ofwel gezondheidstoestand van de patiënt kwam gedurende het onderzoek meerdere malen naar voren. De huidige kwaliteit van leven van de patiënt is één van de gezondheids-gerelateerde factoren die van invloed zijn op de patiënt keuze. Andere samenhangende factoren zijn de urgentie voor behandeling, de ernst van de pijn en de eventuele (visuele) beperking.

Tevens hangt de keuze van een patiënt vaak af van eventuele eerdere ervaringen met de behandeling of met een specifieke zorgaanbieder. Volgens Duits onderzoek is dit de heersende factor. Marang-van de Mheen et al. (7) gaven aan dat de drang om vergelijkingen te maken met andere aanbieders er vaak niet is als de ervaringen goed zijn. Zijn de ervaringen slecht, dan ligt het oriënteren en overstappen naar een ander ziekenhuis of een andere arts veel meer voor de hand. Verder laten mensen zich in hun keuze ook leiden door andere in hun omgeving. Wiedenhofer \& Keppler (8) bestempelen de verwijzingen van artsen en aanbevelingen van familie en vrienden als meest belangrijke bronnen. Echter blijkt de doorverwijzing van de huisarts, onder de patiënten die daadwerkelijk advies vragen, over het algemeen doorslaggevender te zijn dan de adviezen van naaste.

\section{Zorgaanbieder gebonden factoren}

In 25 van de 27 geselecteerde artikelen is onderzoek gedaan naar minimaal één zorgaanbieder gerelateerde factor. Factoren die toe te schrijven zijn aan de organisatie of zorginstelling zijn het aantal werkzame artsen, het aantal beschikbare bedden, het aantal aangeboden diensten en het aantal uitgevoerde operaties. Deze aspecten werken in een positief verband met de instellingskeuze van patiënten. Wanneer de aantallen groter worden, neemt de kans dat patiënten voor die zorgaanbieder kiezen toe. 
Daarnaast zijn de reputatie en de grootte van de instelling van belang. Wanneer het huidige ziekenhuis van een patiënt een slechte reputatie heeft zal de patiënt significant vaker kiezen om een behandeling in een ander ziekenhuis te ondergaan. Wat grootte betreft worden patiënten liever behandeld in een groot ziekenhuis dan in een klein ziekenhuis. Bovendien hebben verschillende onderzoeken aangetoond dat het type eigenaar of type organisatie, de beschikbare technologie of het ontwikkelingsniveau van behandeling en de aanwezige faciliteiten en voorzieningen belangrijke keuzecriteria zijn. Groenewoud et al. (9) spreken in hun onderzoek de invloed van het type ziekenhuis echter tegen. Volgens hen speelt het type ziekenhuis namelijk geen rol in het beslissingsproces. Wel duidelijk is dat de aanwezigheid van veel en goede technische middelen, voorzieningen en faciliteiten een aantrekkingskracht hebben op patiënten en de keuze op een positieve manier beïnvloeden. Andere factoren die door enkele auteurs zijn belicht zijn de hoeveelheid marktcompetitie, de verpleger-patiënt verhouding en de samenwerkingsverbanden of netwerken van de instelling of organisatie. Patiënten worden liever geholpen in een ziekenhuis dat deel uit maakt van een netwerk en dat een groter marktaandeel heeft, ofwel waar minder marktcompetitie heerst.

Verder zijn de eigenschappen en karakteristieken van de artsen en het overige personeel dat werkzaam is bij de zorgaanbieder van invloed. De reputatie van de arts is de meest genoemde factor. Verder zijn de ervaring, de certificatie of nationale erkenning, persoonlijkheid, vriendelijkheid, behulpzaamheid, betrokkenheid en beschikbaarheid van het personeel en hoofdzakelijk van de artsen van belang. Als een arts op veel van deze criteria goed scoort heeft dat een positieve impact en zal de zorgaanbieder eerder worden geselecteerd dan artsen die niet over deze eigenschappen en karakteristieken kunnen beschikken. Tevens is door Abraham et al. (10) gevonden dat de verbondenheid tussen de arts en het behandelprogramma belangrijk wordt geacht. Patiënten prefereren een arts die weet wat er gaande is. Daarnaast kunnen ook factoren als het geslacht en de leeftijd van de zorgaanbieder een rol spelen in de uiteindelijke keuze voor een zorgaanbieder. Zo kiezen vrouwen bij het selecteren van een verloskundige of gynaecoloog vaak voor een jonge vrouwelijke zorgaanbieder. Toch worden leeftijd en geslacht van de zorgaanbieder minder belangrijker gevonden dan de andere genoemde factoren.

Factoren die kunnen worden gerelateerd aan de geleverde kwaliteit zijn ook meegenomen in het onderzoek. Allereerst is de kwaliteit van de geleverde zorg en eventuele nazorg van belang. Patiënten willen graag geholpen worden in een kwalitatief goed ziekenhuis. Toch is het zo dat enkel het beste ziekenhuis aanzienlijk meer patiënten trekt. Een hiermee 
samenhangende factor is de publicatie van en de toegang tot deze kwaliteitsgegevens. Een bevinding is dat ziekenhuizen die op vrijwillige basis kwaliteitsgegevens vrijgeven meer patiënten aantrekken in vergelijking met ziekenhuis die geen data publiceren. Echter geven Dixon et al. (11) aan dat patiënten weinig gebruik maken van de beschikbare informatie over de prestaties van ziekenhuizen. Daarnaast vergelijken verschillende patiënten ook uitkomstmaten als mortaliteit en de overlevingskans alvorens zij een keuze maken tussen zorgaanbieders. Verder worden ook de netheid, de effectiviteit en de veiligheid van de zorgaanbieder in ogenschouw genomen. Bovendien is door Leister \& Stausberg (3) aangetoond dat positieve aandacht, die door de pers en media aan een zorgaanbieder wordt geschonken, van positieve invloed is op de aanbiederkeuze.

\section{Logistieke factoren}

In 17 van de 27 onderzochte artikelen is onder andere aandacht besteedt aan logistieke aspecten. De (reis)afstand die moet worden afgelegd om bij het ziekenhuis te komen heeft een sterke negatieve impact op de keuze van de patiënt. Wanneer andere variabelen niet veranderen betekent dit dat patiënten het dichtstbijzijnde ziekenhuis prefereren. Ook de locatie van de zorginstelling is van belang. In het onderzoek van Weir et al. (5) werd een gunstige ligging van de zorginstelling door $53 \%$ van de respondenten als meest belangrijk beoordeeld. Daarnaast is de locatie voor eventuele nazorg behorende bij de operatie ook bepalend.

Volgens de auteurs van diverse artikelen is ook de reistijd van belang. Over het algemeen zien patiënten op tegen reistijd en hebben ze graag een zorgaanbieder dichtbij huis en in eigen land. Er bestaat een negatieve relatie tussen reistijd en het omzeilen van het dichtstbijzijnde ziekenhuis. Wel is de negatieve waarde die de extra reistijd met zich meebrengt afhankelijk van de behandeling en ziekte (2). Bovendien wordt de relatie negatiever wanneer het reizen door omstandigheden moeilijker wordt. Verder zijn ook de bereikbaarheid van de zorgaanbieder, de reisopties, het comfort en de organisatie van het transport van invloed op de keuze. Een ander punt waar rekening mee wordt gehouden is de parkeergelegenheid.

Een volgende significante keuzefactor is wachttijd. De gemiddelde patiënt bezoekt liever ziekenhuizen met een kortere wachttijd. In het artikel van Marang-van de Mheen et al. (7) wordt de wachttijd voor een operatie bestempeld als meest invloedrijke factor na ervaring en reputatie. Diverse andere auteurs concluderen dat wachttijd slechts één van de vele factoren is die door patiënten in acht wordt genomen. Wachttijd wordt niet gezien als 
dominante factor. Bovendien wordt benoemd dat het de interactie is tussen wachttijd en andere aspecten als reputatie, pijn, kosten, afstand en reismogelijkheden die bepaald of een patiënt wel of niet overstapt naar een andere zorgaanbieder.

\section{Financiële factoren}

Financiële aspecten, die kunnen doorwerken in de keuze van patiënten voor een zorgaanbieder, bleven in de gevonden literatuur vaak buiten beschouwing. In slechts 5 van de 27 onderzochte artikelen is aandacht besteedt aan deze categorie. Victoor et al. (12) geven aan dat de invloed van behandelkosten op de keuze voor een zorgaanbieder afhankelijk is van de zorgverzekering van de patiënt. Wanneer een patiënt verzekerd is voor de behandeling bij een bepaalde zorgaanbieder spelen de kosten geen rol. De kosten van behandeling worden echter wel in ogenschouw genomen wanneer de patiënt hier zelf voor moeten betalen. Het soort zorgverzekering dat een patiënt heeft leidt dan ook tot keuzeverschil. Volgens Leister \& Stausberg (3) kiezen particulier verzekerde patiënten en patiënten met aanvullende private zorgverzekeringen voor een optimaal ziekenhuis, zelfs als het ziekenhuis verder weg gelegen is. Dit terwijl verplicht verzekerde patiënten kiezen voor het dichtstbijzijnde ziekenhuis (3). Bovendien is gevonden dat patiënten met een publieke verzekering en patiënten zonder zorgverzekering vaker dan patiënten met een private zorgverzekering kiezen om te gaan naar een plattelandsziekenhuis of klein stadsziekenhuis (13). Verder is in de studie van Burge et al. (14) uit interviews naar voren gekomen dat het een effect heeft op de keuze voor een zorgaanbieder als patiënten de reiskosten zelf moeten betalen. Het wordt gezien als een last wanneer deze kosten moeten worden gedekt door de patiënten (14).

\section{Discussion/conclusion}

Een beperking van deze literatuurstudie is dat niet alle relevante artikelen zijn meegenomen. Een reden hiervoor is dat in de zoekstrategie bewust is gekozen om de term 'decision making' niet te gebruiken omdat dit heel veel irrelevante resultaten zou geven over onder andere behandelopties. Daarnaast was de volledige tekst van twee artikelen niet toegankelijk via de licentie van Universiteit Maastricht. Verder is in de geïncludeerde studies niet alleen met geobserveerde of werkelijke data gewerkt maar ook met vragenlijsten en interviews. Dit kan bias veroorzaken omdat er dan sprake is van hypothetische keuzes en zelf-gerapporteerde factoren. Ook zijn in deze thesis brede literatuur reviews geïncludeerd, waardoor niet alle artikelen enkel betrekking hadden op snijdende zorg. Bovendien is in die literatuur reviews niet alleen maar literatuur uit het land van onderzoek gebruikt, maar ook uit andere landen. Verder zijn de geanalyseerde 
artikelen afkomstig van een relatief kleine groep landen. Binnen die groep landen is tevens meerdere malen dezelfde behandelingen aan bod gekomen. Daardoor kan het generaliseren van de bevindingen leiden tot een vertekend beeld.

Desondanks kan geconcludeerd worden dat vele factoren van invloed zijn op de keuze voor een zorgaanbieder. Betreffende de weging van de gevonden factoren is het moeilijk aan te geven welke aspecten meer of minder belangrijk zijn. Vaak zijn het namelijk combinaties van factoren of interacties tussen factoren die de doorslag geven. Toch lijken de eerdere ervaringen van patiënten met de zorgaanbieder, de reputatie van de instelling, de wachttijd en de reistijd de meest belangrijke factoren te zijn in het keuzeproces. Deze aspecten zijn relatief vaak onderzocht en telkens invloedrijk bevonden. Eveneens werd het belang van deze factoren door de auteurs zelf vaak al boven het belang van andere aspecten geplaatst. Verder zijn er per patiënt specifieke voorkeuren. Bovendien kan het belang van bepaalde factoren ook verschillen per ziekte of behandeling. Het goed afstemmen van de zorg op de wensen en behoefte van patiënten zal dus moeilijk blijven aangezien er heel veel factoren naar voren kwamen en er ook veel verschillen zijn. Toch is wel duidelijker geworden met welke determinanten patiënten over het algemeen rekening houden in het keuzeproces voor een zorgaanbieder.

Om in de toekomst een duidelijker beeld te krijgen van de bepalende factoren en de mate waarin deze de keuze van patiënten bepalen is meer praktijkonderzoek en een betere samenwerking tussen landen en onderzoekers nodig. Belangrijk daarbij is om niet te gedetailleerd te beginnen maar om eerst de grote lijnen in kaart te brengen, alvorens de rol van elk aspect wordt uitgediept. Tevens moeten de factoren duidelijk worden gedefinieerd in toekomstige onderzoeken zodat er geen onduidelijkheden over kunnen ontstaan. Extra aandacht kan worden geschonken aan de financiële aspecten aangezien daar nog relatief weinig over bekend is. Kortom, meer onderzoek naar de factoren die bepalen welke zorgaanbieder een patiënt kiest is gewenst.

\section{Rol van de student}

Anne van Els was ten tijde van het in dit rapport beschreven onderzoek een bachelor studente Gezondheidswetenschappen die onder begeleiding van Siebren Groothuis en Daan Westra te werk is gegaan. Het algemene onderwerp van het schrijven is door de begeleiders aangedragen. Het opstellen van de onderzoeksmethode, het verzamelen en analyseren van de resultaten en het formuleren van de conclusie, evenals het schrijven van het verslag zijn door de student uitgevoerde taken. 


\section{Referenties}

1. Roh CY, Moon MJ. Nearby, but not wanted? The bypassing of rural hospitals and policy implications for rural health care systems. Policy Studies Journal. 2005;33(3):377-94.

2. Varkevisser M, van der Geest SA. Why do patients bypass the nearest hospital? An empirical analysis for orthopaedic care and neurosurgery in the Netherlands. Eur J Health Econ. 2007;8(3):287-95.

3. Leister J, Stausberg J. Why do patients select a hospital? A conjoint analysis in two German hospitals. Journal of hospital marketing \& public relations. 2007;17(2):13-31.

4. Roh CY, Lee KH. Hospital choice by rural medicare beneficiaries: does hospital ownership matter?--a Colorado case. J Health Hum Serv Adm. 2006;28(3):346-65.

5. Weir R, Feinberg JR, Capello WN. Factors Influencing Patient Choice of Hospital and Surgeon forTotal Hip or Knee Arthroplasty. Indiana Orthopaedic Journal. 2009:55.

6. Moscone F, Tosetti E, Vittadini G. Social interaction in patients' hospital choice: evidence from Italy. Journal of the Royal Statistical Society: Series A (Statistics in Society). 2012;175(2):453-72.

7. Marang-van de Mheen P, Dijs-Elsinga J, Otten W, Versluijs M, Smeets H, Van der Made W, et al. The importance of experienced adverse outcomes on patients' future choice of a hospital for surgery. Quality and Safety in Health Care. 2010;19(6):e16-e.

8. Wiedenhofer D, Keppler S. Free Hospital Choice In Switzerland-Patients' Decision Criteria And Sources Of Information. Interdisciplinary Management Research. 2014;10:763-73.

9. Groenewoud A, Van Exel N, Bobinac A, Berg M, Huijsman R, Stolk E. What influences patients' decisions when choosing a health care provider? Measuring preferences of patients with knee arthrosis, chronic depression or Alzheimer's disease, using discrete choice experiments. Health services research. 2015;1475:6773.

10. Abraham J, Sick B, Anderson J, Berg A, Dehmer C, Tufano A. Selecting a provider: what factors influence patients' decision making? Journal of Healthcare Management. 2011;56(2):99.

11. Dixon A, Robertson R, Appleby J, Burge P, Devlin NJ. Patient choice: how patients choose and how providers respond. London: The King's Fund; 2010.

12. Victoor A, Delnoij DM, Friele RD, Rademakers JJ. Determinants of patient choice of healthcare providers: a scoping review. BMC health services research. 2012;12(1):272.

13. Escarce JJ, Kapur K. Do patients bypass rural hospitals?: Determinants of inpatient hospital choice in rural California. Journal of health care for the poor and underserved. 2009;20(3):625-44.

14. Burge P, Devlin N, Appleby J, Rohr C, Grant J. London Patient Choice Project Evaluation: A model of patients' choices of hospital from stated and revealed preference choice data. Santa Monica: RAND Corporation; 2005 